\title{
A Abordagem Didática da Simulação Virtual no Ensino da Química: Um Olhar para os Novos Paradigmas da Educação.
}

\author{
Gerla Myrcea Lima da Silva ${ }^{1}$, José Francisco de Magalhães Netto ${ }^{1}$, Renato \\ Henriques de Souza ${ }^{1}$ \\ ${ }^{1}$ Programa de Pós-Graduação em Ensino de Ciências e Matemática - PPGCIEM - \\ Universidade Federal do Amazonas - Manaus - AM - Brasil \\ gerlamyrcea@gmail.com, jnetto@icomp.ufam.edu.br, \\ renatohsouza@gmail. com
}

\begin{abstract}
The difficulties of learning chemistry have meant that teachers seek the new educational and methodological alternative responses to change this situation. We used the PhET simulation software with the aim of developing cognition students regarding the interactions occurring in the microscopic particles from substances facilitating the understanding of the chemical content, in particular the state of matter. The research took place in a public school in Manaus, a class of first year of high school. The data obtained from observation and questionnaire were treated following the content analysis. The simulation was effective in learning the content studied.
\end{abstract}

Resumo. As dificuldades de aprendizagem da Química têm feito com que professores busquem nas novas alternativas didáticas e metodológicas respostas para mudar essa situação. Utilizou-se o software de simulação PhET com o objetivo de desenvolver a cognição dos alunos no que se refere as interações que ocorrem nas partículas microscópicas das substâncias, facilitando a compreensão dos conteúdos de Química, em particular, dos estados físicos da matéria. A pesquisa aconteceu numa escola da rede pública de Manaus, numa turma de primeiro ano do Ensino Médio. Os dados obtidos da observação e questionário foram tratados seguindo a Análise de Conteúdo. A simulação mostrou-se eficaz na aprendizagem do conteúdo estudado.

\section{Introdução}

As pesquisas no ensino de Química, nas últimas décadas, têm mantido foco nos paradigmas emergentes da educação pautados na descoberta de novas abordagens e metodologias didáticas que dêem conta de minimizar ou superar as situações críticas de aprendizagem deixadas pelo método tradicional de ensino, os quais reduzem os conhecimentos químicos a teorias desarticuladas e sem quaisquer aproximações com o mundo real dos alunos.

Descontentes com os resultados de aprendizagem das ciências é que pesquisadores e educadores têm buscado nos aparatos educacionais uma forma de melhorar a qualidade do ensino. Neste sentido, entendemos que a integração da tecnologia contribui de maneira significativa para o alcance das metas educacionais propostos nos Parâmetros Curriculares Nacionais $\left(\mathrm{PCN}^{+}\right)$(Brasil 2006).

Os softwares de simulação virtual, em particular o PhET, surgem como uma estratégia diferenciada de ensino pelo fato de possuírem ferramentas de visualização que facilitam a superação dessas dificuldades (Mendes et al. 2015) sendo, portanto, 
produto das relações do homem com a sociedade em resposta aos novos paradigmas educacionais que objetivam superar as lacunas de aprendizagem deixadas pelo método tradicional de ensino. Dentre os pesquisadores que vem acompanhando tais mudanças citamos (Abreu et al.2006, Carpenter 2016, Andrade et al. 2015).

Este artigo tem por objetivo aplicar a simulação virtual PhET e descrever as interações dos estudantes com a ferramenta na aprendizagem do conteúdo Estado Físico da Matéria.

$\mathrm{O}$ artigo está estruturado em 5 seções: $\mathrm{Na}$ seção 2, são descritos os trabalhos correlatos. Na seção 3, apresentamos o desenvolvimento metodológico. Na seção 4, descrevemos os resultados. E, por fim, a seção 5 apresenta as considerações finais e trabalhos futuros.

\section{Trabalhos Correlatos}

Os primeiros softwares computacionais voltados para a Química foram direcionados para a área específica de físico-química, posteriormente, para as áreas de química orgânica e inorgânica. No entanto, somente no final dos anos 90 é que os softwares foram adaptados para atender não somente a pesquisa como também o ensino, servindo como instrumentos de metodologia (Ribeiro e Greca, 2003).

A utilização dos softwares de simulação pode ser concomitante com as aulas expositivas ou em detrimento das práticas laboratoriais, seja pela falta de equipamentos ou por não ter profissionais capacitados para atuarem no mesmo. As tecnologias não substituem os modelos consagrados de ensino, ao contrário, apresentam-se como ferramentas auxiliares em prol de aulas mais dinâmicas, complementando o que essas metodologias não conseguem alcançar em termos de visualização em tempo real do fenômeno abordado na sala de aula.

Muitos pesquisadores tem trabalhado a simulação virtual PhET objetivando melhorar o aproveitamento dos conteúdos de Química e aumentar a participação dos alunos nas aulas. Destacamos seu uso no balanceamento das equações químicas (PhET Balancing-chemical-equations) (Mendes et al.2015), onde os resultados apontam para o fato de que o simulador promove mudanças na concepção de ciências pelo aluno, pois a estratégia favoreceu a construção de conceitos microscópicos; na construção de moléculas (Moore 2014), facilitando a interpretação e formação das fórmulas químicas.

Bertolini et. al (2013) em suas considerações afirmam que a vantagem de usar as ferramentas de simulação no âmbito escolar está na facilidade de acesso e a fácil obtenção destes, pois, pode ser feita em qualquer hora e lugar, sem precisar de alguém para auxiliar, descartando riscos, além de favorecer a aprendizagem.

Os ambientes gamificados o qual têm despertado o interesse de professores e pesquisadores de Química. Com características de um jogo, ou seja, competir, desafiar, ganhar pontos, entre outros, é um game versátil prendendo a atenção dos alunos na busca por resolver determinadas atividades e assim ganhar recompensas, (da Rocha et. al. 2013; Ramos \& Pimentel 2015). De acordo com as pesquisas realizadas pelos autores, as principais contribuições da gamificação estão no ranking disponível no final do jogo, exigindo maior concentração dos participantes nas tarefas executadas e no âmbito pedagógico contribuem para a aprendizagem dos conceitos. 
Os resultados confirmam que por meio dos simuladores, o aluno é instigado à por em prática suas ideias, elaborando suas próprias conclusões, levando-os ao que se pretende no ensino que é aprender. Os critérios de aplicação devem satisfazer os objetivos propostos pelo professor, pois não podem substituir as atividades concretas por mais elaborado que seja o software em uso (Cox 2008). O fato de o computador se transformar de "máquina de ensinar" para ferramenta educacional (Valente 1993) revela que as tecnologias estão cada vez mais sendo aprimoradas para se tornarem recursos didáticos essenciais na educação.

Giordan (2015) faz lembrar que as escolas estão inseridas em diferentes contextos educacionais e tal fato é importante na escolha do software, que deve, sobretudo, levar em consideração as habilidades que o aluno possui. Por oferecer diversas maneiras de acesso aos fenômenos, é que seu uso precisa de ser cuidadosamente planejado e sua aplicação consciente. Portanto, o professor ao associar um software com finalidade educacional na sua metodologia de ensino, deve considerar a fundamentação teórico-pedagógica do mesmo, com o intuito de confirmar se de fato este atende aos objetivos propostos no seu plano de aula.

Devido as características didático e interativo do PhET é que fizemos uso dessa ferramenta no ensino dos estados físicos da matéria mostrando-nos resultados significativos no que se refere à redução das dificuldades de aprendizagem dos alunos na apropriação dos conhecimentos químicos e a aproximação com a Química. Uma das facilidades no uso do PhET está no contato com o objeto, os quais permite, por meio da situação-problema, responder questões levantadas pelo aluno a partir dos seus conhecimentos, valores e linguagens específicas, refletindo sobre suas ações e interpretações, levando-o a erros e acertos, sendo cauteloso na busca de respostas (Carvalho, 2013).

Em suma, as discussões acima não se encerram, pois elas são apenas expressões de um diálogo iniciado. No entanto, consideramos neste trabalho que os discursos dos autores são pertinentes, carecendo o exercício da curiosidade nas atividades que permeiam o ensino e que esta sendo satisfeita, instigue a necessidade de continuar, atribuindo assim mais rigor metódico aos resultados encontrados, além de validar as novas ferramentas didáticas tecnológicas no ensino-aprendizagem das ciências.

\section{Desenvolvimento Metodológico}

O presente estudo foi realizado numa escola da Rede Pública do Estado do Amazonas, Zona Leste, numa turma de $1^{\circ}$ ano do Ensino Médio com 23 alunos, Vespertino, idade entre 14 a 25 anos. O conteúdo abordado foi os Estados Físicos da Matéria. A coleta aconteceu nos meses de setembro e outubro de 2015, 3h/a semanais, totalizando treze encontros. A pesquisa é qualitativa. Como técnica de coleta de dados, optou-se pela observação assistemática e questionário aberto. Assumimos a pesquisa-ação como norteadora das atividades. Os dados abstraídos da observação e questionários foram tratados segundo o instrumento de Análise de Conteúdo (Bardin 2011). Adotamos a metodologia dos momentos pedagógicos (Delizoicov et al. 2011) adaptada da abordagem de Paulo Freire, o qual consiste em dividir a atividade educativa em três momentos pedagógicos, a saber: a) Problematização inicial - Etapa que se apresentam as situações reais que os alunos conhecem e vivenciam; b) Organização do conhecimento - Compreende a sistematização dos conhecimentos descritos no tema e 
V Congresso Brasileiro de Informática na Educação (CBIE 2016)

Anais do XXII Workshop de Informática na Escola (WIE 2016)

na problematização inicial e; c) Aplicação do conhecimento - Na aplicação do conhecimento, os conceitos adquiridos na organização do conhecimento são sistematizados, para posterior análise e interpretação.

\subsection{A Simulação Virtual PhET Estados da Matéria (1.10)}

A simulação virtual foi realizada pelos alunos que desenvolveram a atividade seguindo o tutorial fornecido para cada um deles. No material continha as questões de investigação e instruções para que fizessem observações sistemáticas e anotações da visualização. O simulador PhET (Figura 1) está disponível por meio do link: https://phet.colorado.edu/pt_BR/simulations/category/chemistry, pode ser baixado livremente, versão em português. Além de simular experimentos e modelos químicos, o PhET também faz simulações de conteúdos da Física, Biologia, Ciências da Terra e da Matemática.

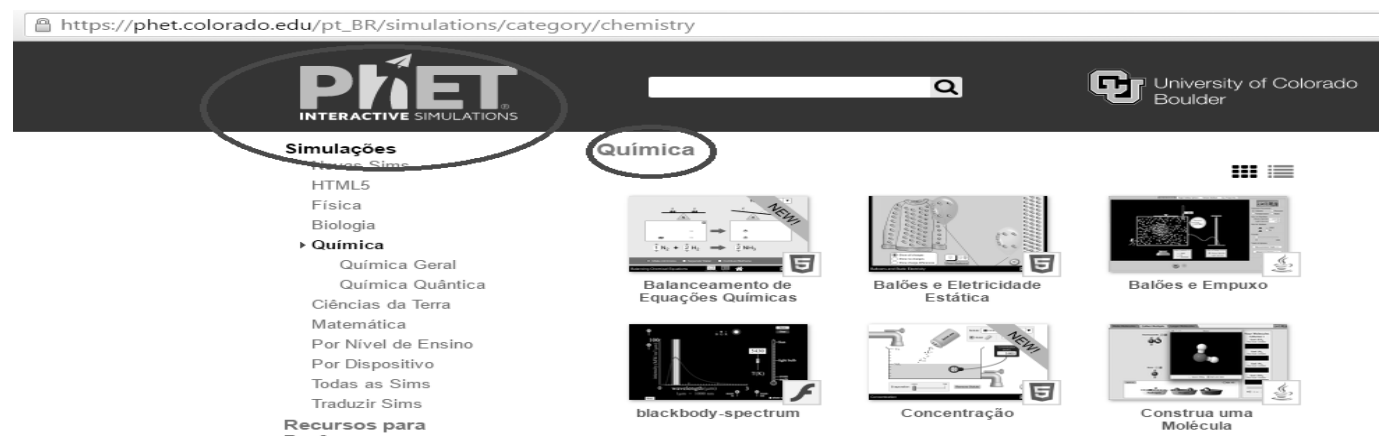

Figura 1: Tela inicia do PhET - Simulações químicas

Fonte: http://phet.colorado.edu/

Dentre as diversas simulações de Química, optamos pelo PhET "Estados da Matéria" (Figura 2) devido abordar de forma bastante didática e interativa, por meio das representações visuais, os conceitos inerentes necessários para a aprendizagem do conteúdo estados da matéria, não alcançados nas aulas explanatórias, dificultando a compreensão do mesmo.

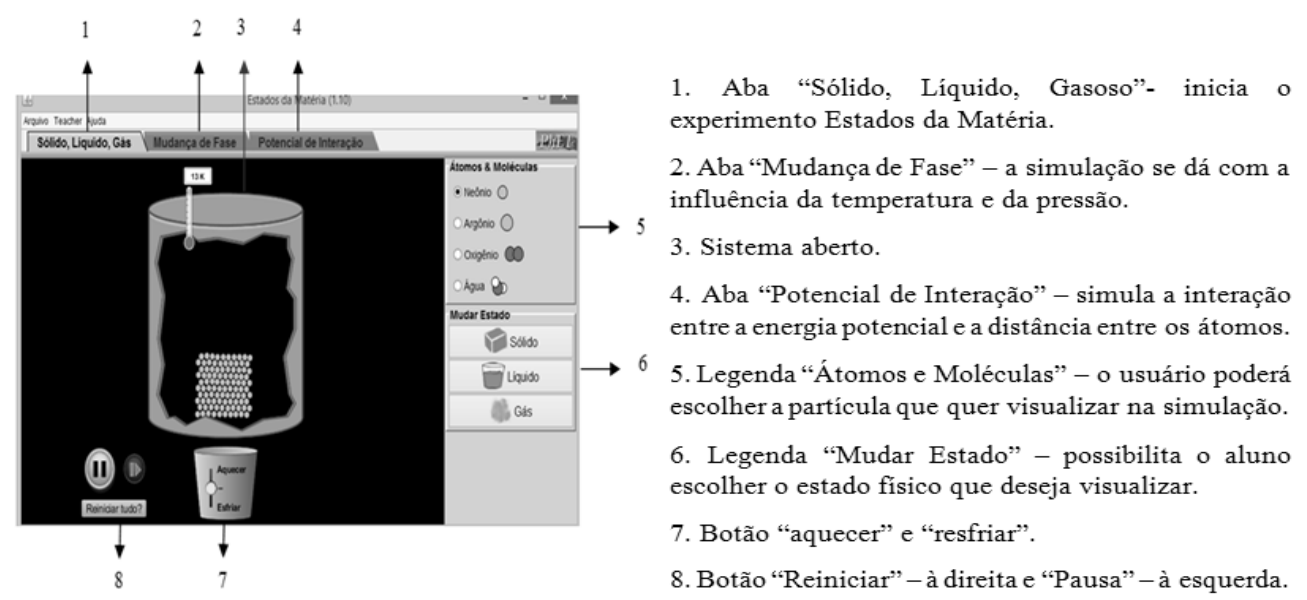

Figura 2: Tela inicial do simulador Estados da Matéria

Fonte: http://phet.colorado.edu/

\section{Resultados e discussões}


V Congresso Brasileiro de Informática na Educação (CBIE 2016)

Anais do XXII Workshop de Informática na Escola (WIE 2016)

\section{a) Problematização Inicial}

Iniciamos a aula fazendo projeções de figuras com eventos do cotidiano, para que assim fizéssemos o levantamento dos "termos" ou conceitos que os alunos tinham a cerca do tema Estados Físicos da Matéria, relacionados ao tema de investigação. A contextualização seguiu o proposto nas Orientações Curriculares Nacionais (OCN) de forma que o conteúdo fosse desenvolvido não para tornar o conteúdo mais atraente ou mais fácil de ser assimilado, mas, oferecendo meios para que o aluno, a partir das suas vivencias, torne suas experiências como fonte inesgotável de conhecimento e aprendizado (Brasil 2006).

Os alunos apresentaram dificuldades em lembrar os conceitos estudados no $2^{\circ}$ bimestre do ano letivo, além da falta de relação do conteúdo com o cotidiano. O levantamento dos conhecimentos prévios foi classificado nas categorias: conceito, mudança de fase e influência de fatores externos, conforme o Quadro 1.

Quadro 1. Classificação dos “termos” ou Conceitos Atribuídos pelos Alunos

\begin{tabular}{c|c}
\hline Classificação & "Termo" ou Conceitos \\
\hline Conceito & Como é a matéria; Sólido; Líquido; Gasoso \\
\hline Mudança de Fase & $\begin{array}{c}\text { Condensação; Saindo do estado sólido para o } \\
\text { estado líquido; Liquefação; Descongelando; } \\
\text { Derretendo; Vaporização }\end{array}$ \\
\hline $\begin{array}{c}\text { Influência de } \\
\text { fatores externos }\end{array}$ & $\begin{array}{c}\text { Temperatura; Calor; Abaixamento da } \\
\text { temperatura; "decomposição da naftalina" na } \\
\text { temperatura; Mudança de }\end{array}$ \\
\hline
\end{tabular}

Fonte: Elaboração Própria

Os resultados apontam a necessidade de reflexão por parte dos professores no que diz respeito à contextualização dos conhecimentos químicos e sua relação com o cotidiano para facilitar a aprendizagem dos conceitos químicos pelos alunos. É necessário que o professor supere essa forma de ensino dissociado da vida (Schnetzler 2004) e leve o aluno a ver que a química está associada a maior parte das situações do cotidiano.

A partir dos "termos" ou conceitos levantados, os alunos iniciaram a elaboração de "problemas", objetivando serrespondidas durante a abordagem do conteúdo. A atividade proposta era nova para eles e até o presente momento nunca tinham sido convidados a formularem suas próprias perguntas e, consequentemente, buscar respostas para a solução das mesmas. Sem saber como iniciar o aluno A12 indagou: “Mais eu nem sei como fazer uma pergunta. Eu não sei fazer essa coisa não!” (A12).

Neste momento, a aluna A1 exclamou: "Professora, eu mesmo tenho que elaborar a pergunta? Eu não sei como fazer isso, me ensine!" (A1); A dificuldade de domínio da língua materna foi nítida. Infelizmente, nossa cultura não ensina a elaborar a "pergunta certa" com o intuito de desenvolver habilidades de raciocínio ou o ato de questionar dos alunos.

É preciso que os professores desafiem os alunos a olhar diferente às situações vivenciadas no cotidiano, pois, quando os alunos respondem a questões que são formuladas a partir dos seus conhecimentos, valores, práticas e linguagens, isso mostra 
V Congresso Brasileiro de Informática na Educação (CBIE 2016)

Anais do XXII Workshop de Informática na Escola (WIE 2016)

que eles passaram a ver as diversas situações que os cercam cientificamente, no entanto, é preciso que os estudantes sejam inseridos nesse universo, (Carvalho 2013). Os alunos formaram grupos e aos poucos foram se envolvendo e o diálogo sendo intensificado.

No Quadro 2 a seguir, estão listados na íntegra os problemas formulados pelos alunos.

Quadro 2. Categorização das Perguntas Construídas Pelos Alunos

\begin{tabular}{c|l}
\hline CATEGORIAS & \multicolumn{1}{c}{ PROBLEMAS ELABORADOS } \\
\hline Fenômeno Físico e Químico & $\begin{array}{l}\text { O que é um fenômeno químico e físico? Quando } \\
\text { podemos saber quando está acontecendo as mudanças e } \\
\text { quando é um fenômeno físico? }\end{array}$ \\
\hline Mudança de Estado Físico & $\begin{array}{l}\text { O que é fusão? Qual o nome se dá a mudança de um } \\
\text { estado para o outro? E que existe alguma diferença qual } \\
\text { é essa diferença? }\end{array}$ \\
\hline \multirow{5}{*}{ Temperatura } & $\begin{array}{l}\text { Qual é o ponto de ebulição do líquido para gasoso? } \\
\text { Quando uma panela está no fogo e a mesma esta } \\
\text { fervendo o que acontece? Qual é o nome que podemos } \\
\text { denominar essa fase? Quando botamos água para ferver } \\
\text { em uma panela, o que faz ela muda para o estado } \\
\text { gasoso? }\end{array}$ \\
\hline Mudanças do Clima & $\begin{array}{l}\text { Qual a ligação de estender roupa com estado físico e } \\
\text { matéria? O que faz ocorrer as mudanças climáticas? O } \\
\text { que o aquecimento global apresenta no estado físico da } \\
\text { matéria? }\end{array}$ \\
\hline
\end{tabular}

Fonte: Própria do Autor

Nas quatro categorias de análise geradas observou-se que os alunos ainda não assimilaram conceitos básicos referentes ao conteúdo, além de apresentar dificuldades em relacionar o assunto com as observações feitas no cotidiano, como sua ocorrência e aplicação. A abordagem aplicada provocou uma mudança de atitude nos alunos, onde a forma como se comportavam no final de cada aula era totalmente diferente das que tinham inicialmente.

A análise dos resultados acima é o que chamamos de verdadeira motivação pela ciência, ou seja, a descoberta pelo interesse, pela aproximação com o mundo, das indagações sobre a estrutura e a natureza, o interesse em fazer perguntas e procurar as próprias respostas, importante no processo de construção e apropriação do conhecimento científico, no qual dependerá de como ele está aprendendo, ou seja, do tipo de atividade de ensino e aprendizagem que o aluno está envolvido, (Pozo \& Crespo 2009).

\section{b) Organização do Conhecimento (Atividade com o Simulador PhET)}

Nesta etapa trabalhamos a interdisciplinaridade para tentarmos reduzir as lacunas conceituais de aprendizagem do conteúdo de estudo, levantado na problematização feita pelos alunos. Portanto, convidamos o professor da disciplina de Física do horário matutino para que, com seus conhecimentos e método de ensino pudesse contribuir para a aprendizagem do conteúdo estados físicos da matéria. A interdisciplinaridade oportunizou os alunos a compreenderem a dependência entre os 
conhecimentos das ciências química e física como ponto de partida para aprendizagem significativa dos conceitos estudados na sala de aula.

A educação interdisciplinar é um diálogo que acontece entre os diferentes saberes disciplinares mediando a (re) construção do conhecimento com a cultura científica de cada ciência, formas de abordagens e ações. Assim, a enculturação contextualizada na Química associada à interdisciplinaridade sólida suscita conhecimentos adquiridos do ser humano na sua totalidade, a fim de ampliá-los em um novo contexto, marcado pelos paradigmas socioambiental (Brasil 2006).

Posteriormente, seguimos para o Laboratório de Informática, onde continuamos o conteúdo usando o simulador PhET. Devido às características didáticas do simulador de visualizar e interagir com as partículas microscópicas por meio dos modelos representativos, a abordagem usando esta ferramenta contribuiu significativamente para a aprendizagem do conteúdo constatado a partir do desenvolvimento cognitivo dos alunos observados na maneira como passaram a perceber, compreender e relacionar os conceitos a partir das interações realizadas pelo simulador.

Embora não tivessem tido contato com um software de simulação e o desuso do computador na escola, os alunos demonstraram na prática ter domínio e habilidade da ferramenta computacional, interagindo facilmente com o simulador, como mostrado na figura 1. Seguindo o tutorial respondiam as questões de investigação propostas.

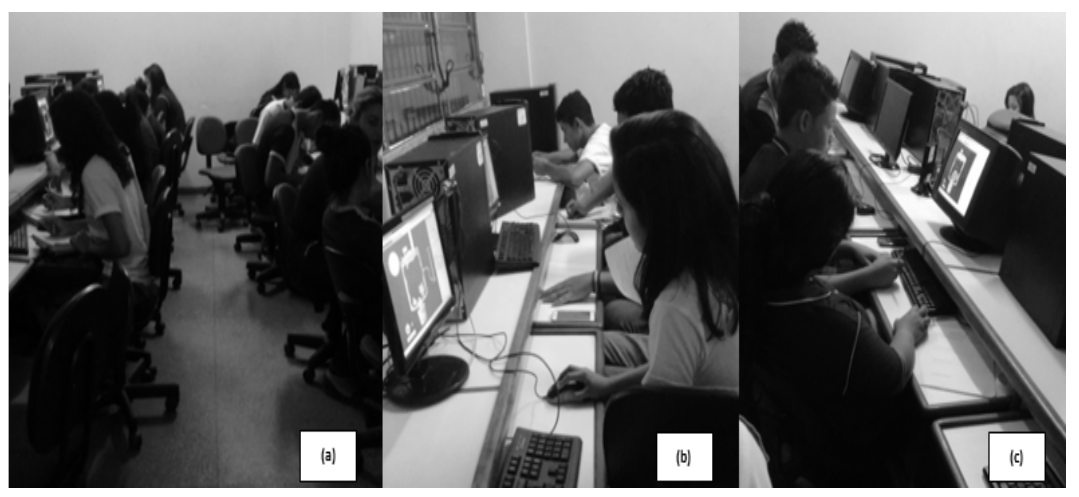

Figure 1. Uso do Simulador PhET

Fonte: Própria do Autor

As tecnologias já estão integradas na vida social e cultural dos estudantes e é dever da escola oportunizar os alunos a terem acesso a esses recursos que ora encontram-se disponíveis nas instituições públicas estaduais, mas, são pouco usadas como recurso didático ou mesmo são inseridas nos planejamentos bimestrais com o intuito de melhorar a qualidade do ensino. Na questão 1 , os alunos foram perguntados se ao aquecer as partículas sólidas num sistema fechado, haveria alteração no estado físico da matéria e de que maneira a pressão influenciara nesta mudança, o aluno A6 respondeu que "elas perdem energia e passam para o estado líquido e ao aumentar a pressão, a temperatura diminui e o átomo perde a energia e entra para o estado gasoso".

Identificamos na resposta do aluno A6 uma confusão conceitual, pois na pergunta afirmamos que as partículas são aquecidas. Isso implica dizer que a temperatura aumenta e, conseqüentemente, a pressão também aumenta, e não o inverso como afirmou o aluno. A resposta esperada/adequada para o fenômeno físico em 
discussão seria de que se o sistema é aquecido, logo, acarreta no aumento da temperatura e consequentemente da pressão das partículas/moléculas, implicando, portanto, na mudança do estado sólido para o estado líquido e posteriormente para o gasoso. A resposta do aluno A12 está dentro do que consideramos esperado/adequado, pois as relações conceituais foram feitas corretamente, como descrito: "Ao aquecer o estado sólido as partículas começam a vibrar com intensidade e se agitam. A pressão é aumentada". Quando bem articulado e planejado, os simuladores sinalizam resultados significativos na aprendizagem dos conceitos químicos, especialmente, dos fenômenos microscópicos de difícil visualização.

$\mathrm{Na}$ segunda e última questão pedimos para que $\mathrm{s}$ alunos descrevessem o comportamento da partícula/molécula no estado gasoso ao sofrer resfriamento. $\mathrm{O}$ aluno A12 respondeu que "o estado gasoso ao se resfriar, as partículas começam a se movimentar com pouca agitação, quanto mais aumenta o resfriamento, as partículas vão se juntando até ficarem com pouca agitação". O aluno A12 foi bem pontual em descrever o resfriamento das partículas e usou com apropriação os conceitos científicos do fenômeno físico em questão, o que nos permite inferir que ele sentiu menos dificuldade em integrar os conceitos aprendidos na descrição do fenômeno simulado.

\section{c) Aplicação do Conhecimento}

Solicitamos que os alunos reelaborassem as perguntas formuladas na problematização inicial usando os conhecimentos adquiridos nos encontros anteriores, reelaborando-as com maior rigor e cientificidade. As perguntas estão descritas no quadro 2 a seguir:

\section{Quadro 2: Reelaboração dos Problemas Iniciais}

\begin{tabular}{ll}
\hline CATEGORIAS & \multicolumn{1}{c}{ PROBLEMAS REELABORADOS } \\
\hline $\begin{array}{l}\text { Fenômeno Físico e } \\
\text { Químico }\end{array}$ & $\begin{array}{l}\text { Qual a diferença entre fenômeno químico e físico? } \\
\text { Que relação as mudanças tem com a temperatura e a } \\
\text { pressão? }\end{array}$ \\
\hline $\begin{array}{l}\text { Mudança de Estado } \\
\text { Físico }\end{array}$ & $\begin{array}{l}\text { Como podemos saber o momento que ocorrem as } \\
\text { mudanças de estados físicos da matéria? }\end{array}$ \\
\hline $\begin{array}{l}\text { Efeito da } \\
\text { Temperatura }\end{array}$ & $\begin{array}{l}\text { No ponto de ebulição, o que define a mudança de } \\
\text { fase e por que as moléculas ficam muito agitadas } \\
\text { quando aquecidas? }\end{array}$ \\
\hline \multirow{2}{*}{ Mudanças do Clima } \\
\hline $\begin{array}{l}\text { Qual a ligação entre as mudanças climáticas e o } \\
\text { aquecimento global e sua relação com o estado físico } \\
\text { da matéria? }\end{array}$
\end{tabular}

\section{Fonte: Própria do Autor}

Observamos que as perguntas já apresentam mais rigor e objetividade. Identificamos as palavras "relações, "temperatura", "pressão", "moléculas" completando corretamente o sentido da pergunta. Portanto, os resultados apontam que houve mudanças significativas na aprendizagem conceitual e cognitiva dos alunos, sendo perceptíveis tanto na linguagem escrita, como também na organização lógica do real sentido dos conceitos por eles estudados.

Nas respostas obtidas por meio do questionário de avaliação da abordagem usando a simulação virtual, os alunos responderam: "[...] aprendi muito mais e minha mente abriu pra esse universo da química (A1)”; "Ótima, conseguimos visualizar 
V Congresso Brasileiro de Informática na Educação (CBIE 2016)

Anais do XXII Workshop de Informática na Escola (WIE 2016)

melhor, podemos compreender com uma facilidade imensa e imediata (A3)"; "Eu avalio como uma boa forma de compreender e entender mais sobre a matéria (A6)".

Os resultados apontam que a abordagem usando o software de simulação virtual PhET mostrou-se como eficaz no ensino e aprendizagem dos conceitos químicos, pouco assimilados apenas pelo método tradicional de ensino, que dificulta a construção dos modelos mentais que facilitam o entendimento e compreensão das interações existentes entre as partículas, bem como a influência dos fatores externos.

\section{Considerações finais e Trabalhos Futuros}

A análise dos registros mostrou que a abordagem do tema por meio da simulação virtual foi bem aceita pelos alunos, pois, permitiu visualizar o fenômeno microscópico em tempo real a partir das interações existentes entre as partículas. A aprendizagem do conteúdo estados físicos da matéria foi evidenciada ao longo dos encontros por meio dos exercícios avaliativos, levantamento de discussões e na maneira como descreviam o fenômeno usando os conhecimentos científicos aprendidos nas aulas.

Enquanto ferramenta de aprendizagem, a simulação virtual contribuiu significativamente com os modelos representativos dos fatores externos (temperatura e pressão) e interações das partículas para a assimilação e compreensão dos conceitos químicos dos estados físicos da matéria. Por suas características interativa, dinâmica e de fácil manipulação, a simulação virtual despertou a curiosidade e o interesse dos alunos que se divertiam enquanto aprendiam. $\mathrm{O}$ simulador PhET é bastante abrangente e oferecem simulações em todos os campos da Química, podendo ser utilizado em todas as séries do Ensino Médio.

Diante disso, como trabalho futuros pretendemos disseminar nas escolas da rede pública estadual de Manaus os resultados positivos que podem ser alcançados com o uso dos aparatos tecnológicos nas abordagens didáticas e metodológicas do ensino da Química, os quais despertam a curiosidade dos alunos e os motivam buscar suas próprias respostas para os problemas que surgem durante a investigação dos fenômenos. Com efeito, alcançaremos os profissionais envolvidos no processo educativo para que possam juntos repensar novas estratégias que culminem na aprendizagem significativa dos alunos, além de por em prática as propostas dos documentos oficiais da educação.

\section{Referências}

Andrade, B. A. et al. (2015) Big Bang: Uma Ferramenta para Auxiliar no EnsinoAprendizagem da Classificação Periódica dos Elementos Químicos. Anais do XXI Congresso da SBC. Workshop de Informática na Escola. Campo Grande, MS, Brasil. 2006.

Abreu, Marlon F., et al. (2006) Utilizando Objetos de Aprendizagem no processo de ensino e aprendizagem de química no ensino médio: o caso dos óxidos e da poluição atmosférica. Anais do XXVI Congresso da SBC. WIE I XII Workshop de Informática na Escola. Campo Grande, MS, Brasil.

Bardin, L. (2011) Análise de conteúdo. 3. reimp. Lisboa: Edições, v. 70.

Bertolini, C. T., Braga, J. C., Pimentel, E., \& Ramos, S. (2013). Laboratório Virtual interativo para reprodução de experimentos de química através de dispositivos 
móveis. In Anais do Simpósio Brasileiro de Informática na Educação. (Vol. 24, No. 1, p. 285).

Brasil. SEB. (2006) Orientações Curriculares para o Ensino Médio. Ciências da Natureza, Matemática e suas Tecnologias. Brasília: MEC, SEB.

Carpenter, Y.; Moore, E. B.; Perkins, K. K.(2016) Representations and Equations in an Interactive Simulation that Support Student Development in Balancing Chemical Equations.

Carvalho, A. M. P. (2013) Ensino de Ciências por investigação: condições para implementação em sala de aula. São Paulo: Cengage Leatrning.

Cox, K. K. (2008) Informática na Educação Escolar. $2^{\mathrm{a}}$ ed. -Campinas, SP: Autores Associados. - (Coleção polêmicas do nosso tempo, 87).

da Silva, J., et al. (2015) Mudança Conceitual em Óptica Geométrica Facilitada Pelo Uso de TDIC. Anais do Workshop de Informática na Escola. Vol. 21. No. 1.

da Rocha Fernandes, Anita Maria, and Fernando Santos Castro. "Ambiente de Ensino de Química Orgânica Baseado em Gamificação." Anais do Simpósio Brasileiro de Informática na Educação. Vol. 24. No. 1. 2013.

Delizoicov, D. et al. (2011) Ensino de Ciências: fundamentos e métodos. 4. ed. São Paulo: Cortez.

Giordan, M. (2015). Análise e Reflexões sobre os Artigos de Educação em Química e Multimídia Publicados entre 2005 e 2014.

https://phet.colorado.edu/pt_BR/simulations/category/chemistry. Acessado em: 03/06/16.

Mendes, A. P. et al. (2015) O Uso do Software PhET como Ferramenta para o Ensino de Balanceamento de Reação Química. Revista Areté: Revista Amazônica de Ensino de Ciências, v. 8, n. 16.

Moore, E. B., et al. (2014): Awakening Dialogues - Advancing Science Education Research Practices and Policies. Proceedings of the National Association for Research in Science Teaching, Annual International Conference. National Association for Research in Science Teaching.

Ramos, S.; Pimentel, E. P. (2015) "VirtuaLabQ Ambiente Gamificado para a Prática Experimental de Transformações Químicas." Anais do Simpósio Brasileiro de Informática na Educação. Vol. 26. No. 1.

Ribeiro, A. A.; Greca, I. M. (2003) Simulações computacionais e ferramentas de modelização em educação química: uma revisão de literatura publicada. Química Nova, v. 26, n. 4, p. 542-549.

Schnetzler, R. P. (2004) A Pesquisa no Ensino de Química e a Importância da Química Nova na Escola, Química Nova na Escola, n. 20, p. 49-54.

Pozo, I.P.; Crespo, M. A. G.(2009) A aprendizagem e o ensino de ciências: do conhecimento cotidiano ao conhecimento científico. 5. ed. Porto Alegre: Artmed.

Valente, J.A. (1993) Diferentes usos do computador na educação. Computadores e Conhecimento: repensando a educação: 1-23. 